\title{
Who You Know vs. What You Know: The Impact of Social Position and Knowledge on Team Performance
}

\author{
Michael J. Ashworth \\ Kathleen M. Carley \\ Carnegie Mellon University, Pittsburgh, Pennsylvania, USA
}

\begin{abstract}
Organizational behavior theories generally agree that human capital is critical to teams and organizations, but little guidance exists on the extent to which such theories accurately explain the relative contributions of individual actors to overall performance. Using newly created network measures and simulations based on data obtained from a software development firm, we investigate the relative effectiveness of social network theory and resource dependency theory as predictors of individuals' contributions to team performance. Our results indicate that individual impacts on team performance are more closely associated with knowledge and task dimensions than with social network structure. Furthermore, given that knowledge may be assessed a priori, these factors provide useful guidance for structuring teams and predicting team performance.
\end{abstract}

Keywords: group performance, social networks, knowledge networks, resource dependency, human resource management

Teams require the right combination of personalities, capabilities, and knowledge to achieve maximum effectiveness, but organization charts and personnel evaluations notwithstanding, critical contributors to a team's performance are far from obvious (Prietula \& Simon, 1989).

Authors express appreciation for the insightful observations of Patrick Doreian and the anonymous JMS reviewers and acknowledge the helpful comments offered by Dan Brass, Rich Burton, David Krackhardt, Bill McKelvey, Michael Prietula, and Marshall Van Alstyne on earlier versions of this paper. Funding for this work was provided by the National Science Foundation IGERT grant no. 9972762, the Carnegie Mellon University (CMU) School of Computer Science, the CMU Center for Computational Analysis of Social and Organizational Systems, the William Larimer Mellon Foundation, and the CMU Tepper School of Business.

Address correspondence to Michael J. Ashworth, Carnegie Mellon University, 5000 Forbes Avenue, Smith Hall 231, Pittsburgh, Pennsylvania 15213, Tel: (412) 519-5149, E-mail: ashworth@cmu.edu 
This situation arises because work groups are composed not only of people and their individual behaviors but also of the cultural backgrounds, skills, education, financial and physical resources, and other distinctive traits these "human capital endowments" bring to the organization (Becker, 1975; Mincer, 1970; Stewart, 2001). Social network theories suggest that the types and degrees of an individual's relationships in social and communication networks are key impactors of group performance, while resource dependency theory suggests that non-social factors such as knowledge and skill figure at least as prominently as social dimensions in determining such performance. Our objective in this study is to investigate the relative ability of social network theory versus resource-based views to explain the criticality and performance of human capital at a team level in an organization.

In the following sections, we draw on some of the relevant research to provide our motivation and show how our conjectures extend existing theories of individual productivity, group performance, and social networks. We then describe our theoretical propositions, propose a research methodology, introduce empirical data, and present specific results of our analysis. We conclude with a wider discussion of contributions, limitations, and opportunities for further research. Our results provide the first empirical evidence that the extent of an actor's contribution to group performance is more related to the individual's knowledge and tasks than to the individual's position in the team's social network. From a practical standpoint, since objective evaluations of skills and knowledge can be conducted prior to team formation, as opposed to evaluations of social network positions well after teams are established, our measures and methodology offer useful approaches to structuring teams and predicting their performance.

Several areas of organizational behavior literature stress the importance of human capital, including theories of power (Emerson, 1962), complexity (Perrow, 1984, 1986), resource dependency (Hickson, Hinings, Lee, Schneck, \& Pennings, 1971; Wernerfelt, 1984), leadership (Graen, 1976), knowledge and learning (Carley \& Hill, 2001; Hollenbeck, Ilgen, Phillips, \& Hedlund, 1994; Hollenbeck et al., 1995), and social and human capital (Coleman, 1988). While all of these perspectives are related, power and leadership in particular are clearly linked to knowledge and learning due to the fact that such power rests primarily on the control of resources possessing appropriate knowledge and skill (Leavitt, 1996; Mintzberg, 1983), but it is not clear whether social or knowledge factors matter more in determining individual contributions to team performance. Recent work by Ahuja, Galletta, and Carley (2003) found that individual centrality is a strong predictor of individual performance and plays a mediating 
role with respect to other performance factors such as functional and communication roles, but their study only indirectly incorporates knowledge. Kline and McGrath (1998) suggest that meeting objectives with high quality (accuracy) is the most important evaluative criterion for team performance, but their model fails to link team performance to social position or knowledge of individual actors. Other studies have established the importance of task-related knowledge and group familiarity (Hinds, Carley, Krackhardt, \& Wholey, 2000; Littlepage, Robison, \& Reddington, 1997), while still others have linked group performance to cognitive structures such as group experience and transactive memory (Carley, Kiesler, \& Wholey, 1993; Liang, Moreland, \& Argote, 1995), shared mental models (Espinosa et al., 2002), and group "meta-knowledge" (Larsen \& Christenson, 1993). Fleishman and Zaccaro (1992) offer a taxonomy that includes team resource distribution as a variable but do not extend their topology to a detailed assessment of team members' knowledge, skill, and task-based capabilities. Kiesler, Wholey, and Carley (1994) discuss the importance of coordination, structure, and communication in determining individual contributions to software team performance, but their work stops short of offering guidance on the relative importance of knowledge versus other factors (although the authors do suggest-as this paper attempts to illustrate - that such research should encompass both the social and the efficiency effects of team coordination). Literature on organizational learning shows the clear relationship of knowledge to organizational productivity (Argote, 1999; Levitt \& March, 1988). In the work of Herriott, Levinthal, and March (1985) and Pisano, Bohmer, and Edmondson (2001), for example, differences in productivity across firms are linked to cumulative experience and initial competences of individual actors. Although these inquiries confirm that knowledge is a major determinant of team performance, they do not focus objectively on each individual's ex ante knowledge relative to social position.

In contrast to the literature on organizational learning, theories of social networks suggest that, while skills are one of many elements affecting team performance, such performance may be primarily dependent on the power and influence structure of a group's social network (Burt, 1992; Brass, 1984; Everett \& Borgatti, 1999; Freeman, 1979; Jones, Hesterly, Fladmoe-Lindquist, \& Borgatti, 1998; Krackhardt, 1999). The social network view posits that the contributions of individual actors within a team framework depend fundamentally on the relations between actors as opposed to actors' resources or knowledge (Burt, 1992). Indeed, in this paradigm, the relations themselves are productive resources (Coleman, 1988). The structural character of actors' social linkages with other actors, hence their social 
network positions, influence the extent to which they are economic producers (Granovetter, 1985; Lin, 2001). While individually and collectively insightful, such theoretic approaches subsume knowledge as a mediating factor while primarily emphasizing social, friendship, communication, and advice networks, thus failing to incorporate a more comprehensive and analytical view of other critical aspects of group performance such as education, skill, and experience.

Although existing literature does not explicitly compare the impact of social position and knowledge on team performance, research in both industrial-organizational psychology and organization strategy has established connections between individual and collective intellectual capital, firm strategic advantage, and organizational performance (Coff, 1997; Coff, 1999; Wernerfelt, 1984). For example, Goodman, Lerch, and Mukhopadhyay (1994) offer Thompson's (1967) framework as a means of explaining potential variation in the levels of individual contributions to organizational productivity, but their final analysis calls for more detailed empirical work to investigate facilitators and inhibitors of individual performance contributions.

Other research offers the notion of task criticality as a partial explanation of the link between individual actors' productivity and organizational effectiveness. Notably, Brass (1984) and Hinings et al. (1974) evaluate task criticality in terms of an actor's "non-substitutability" and the number of connections the actor has to other actors for inputs and outputs related to her or his task. Similar recognition of the importance of task and knowledge attributes in organization networks can be traced to Pfeffer (1981) and Mechanic (1962), with their concept of "irreplacibility," and to Crozier (1964), who emphasized task criticality in his analysis of an engineering group's performance in a French tobacco-processing plant.

The primary motivation for this paper is to build on these resourcebased views by advancing theory at a finer-grained level on the contributions of individual knowledge to team performance. Our motivation is predicated on the post-Weberian recognition that teams are comprised of individuals as opposed to mere placeholders (Goodman, 1998), the growing importance of skill and knowledge elements in modern organizations (Fullerton \& Toossi, 2001), and the need to incorporate a dynamic understanding of those elements when seeking to fully understand and manage critical human assets (Senge, 1990).

To explore these facets more formally, we developed three propositions based on the implications of social network and resource dependency theories. Because social network theory does not explicitly incorporate task and knowledge dimensions except in a descriptive sense, following Brass's logic (1984) the theory may not always 
reliably link all critical actors to team performance. If such theory alone is relied upon to investigate employee contributions to performance, it may accurately identify actors who are key in terms of social connections but not necessarily key in terms of greatest performance impact. Conversely, the application of social network theory as a sole basis for linking individuals to group performance may lead to the identification of actors as critical when they may not be critical in terms of group performance impact. These types of errors are analogous in many ways to "false negative" and "false positive" statistical errors, and for convenience we shall be referring to them as such throughout the remainder of the paper. ${ }^{1}$ Thus, our first proposition is as follows:

P1a: Social network theory alone does not reliably predict all critical human actors on a team as determined by their performance impact;

$\boldsymbol{P 1 b}$ : Social network theory alone has an unacceptably high tendency to identify human assets as critical when they may not be.

The reliability and acceptability criteria for our purposes are based on the area under the corresponding receiver operating characteristic (ROC) curve being greater than 0.80 , which is generally considered to indicate good to excellent performance of a measurement test construct (Swets, 1995; Tape, 2002).

One of the primary corollaries of our thesis in this study is that resource-based views of knowledge and task relations in organizations are more reliable predictors of individuals' contributions to performance than those provided by social network theory alone. Accordingly, we further suppose that

P2: Knowledge elements of resource dependency theory can be used to idencctify critical human assets without unacceptably high levels of false negatives and positives.

Finally, we believe that it will be useful to show whether both theories acting together can be relied upon to more accurately connect

\footnotetext{
${ }^{1}$ We use the analogy of Type I and Type II errors strictly for convenience in describing the efficacy of measures used to evaluate the hypotheses. We do not imply that existing theories are invalid because they exhibit false negatives. Instead, we are suggesting that while theories of organization science may reflect Popper's falsifiability criterion, those theories which can be shown to be consistently less falsifiable (viz., exhibiting consistently fewer false negatives or false positives) are arguably more robust.
} 
individual actors' contributions to overall group performance. Based on this premise, we propose the following:

P3: A combined application of resource dependency and social network theories enables the reliable identification of all critical human assets on a team.

\section{METHOD}

To provide a realistic framework in which to evaluate these propositions, we first introduce data obtained from a high-tech firm focused on software development. Software development teams, in general, exhibit high levels of knowledge intensity (Kiesler et al., 1994), making this data selection particularly relevant to our analysis. After describing our data set, we introduce our theoretical model and describe the steps in our research methodology.

\section{Description of Data Set}

The data we use in our study relate to a team of 16 information technology (IT) professionals responsible for the programming and implementation phases of a multi-phase IT development project. The team members' specific roles are summarized in Appendix A ("Actor Vector") and Figure 1.

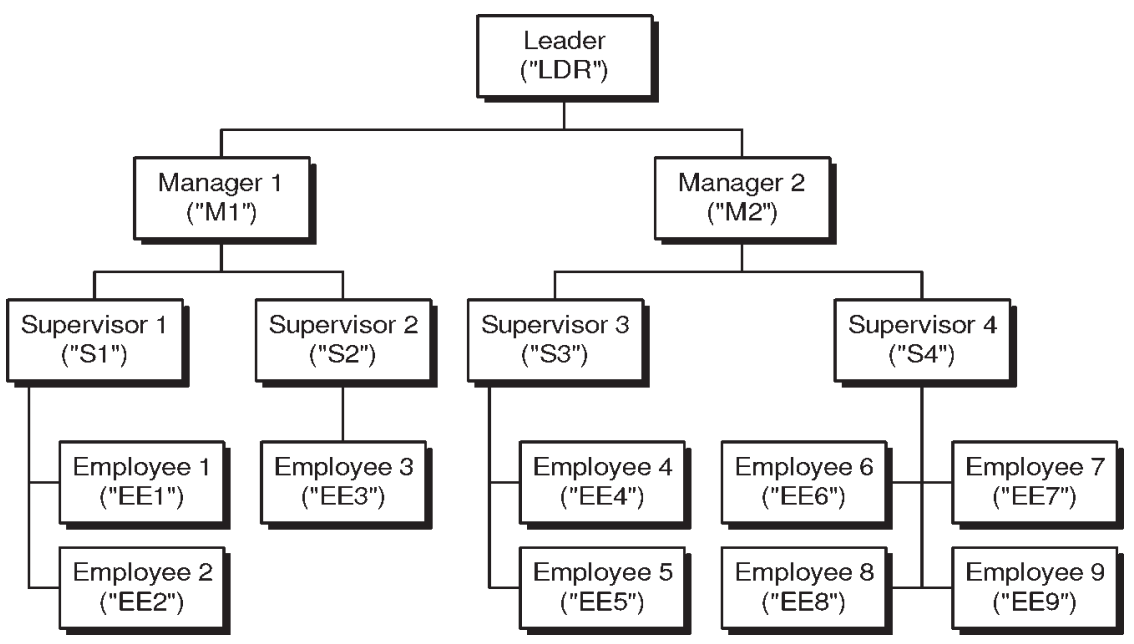

FIGURE 1 Software team organization. 
As shown in the organization chart, there is a leader (project manager), two assisting managers, four supervisors and nine employees, all with skills ranging from artistic design to specialized programming expertise. Since the company would not permit us to access private employee communication records or to conduct a formal social network survey, we faced a potentially vexing primary data problem in developing the social network matrix required for calculating traditional centrality measures. To address this problem, we applied a triangulation approach used successfully in a number of research disciplines (Benbasat, Goldstein, \& Mead, 1987; Bonoma, 1985; Bredo \& Feinberg, 1982; Jick, 1983; Maxwell, Bashook, \& Sandlow, 1986; for more general treatments, see also Cook \& Reichardt, 1979; Glaser \& Strauss, 1967; Van Maanen, 1983; Yin, 1984), combining qualitative methods including observation, interviews, and iterative data collection with quantitative methods. Deriving the social network with such an approach both meets our present methodological requirements and offers a useful pedagogic tactic to the typical organization seeking to perform similar analyses but finding itself (whether for practical or policy reasons) in the similar position of not being able to conduct a more standard social network survey.

Hence, as the first step in modeling the social network, we conducted iterative interviews with key team leaders regarding task-oriented interaction patterns and asked them to provide their view of the team's network of social interaction, with an unvalued, bi-directional tie between actors A and B being defined as "A and B are observed communicating regularly throughout the day." While "regularly" was subject to some interpretation, the distinction rested on the managers' assessments of average frequency and duration of communications, with estimates tending to be relatively bi-polar (that is, communications between two given actors were either comparatively high or low, with a "high" level indicating that a tie exists and a "low" level indicating that no tie exists between the actors). Given both the constant proximity of managers to team members and the open, low-divider work space design, such observations were easily made throughout the project, and, according to Krackhardt (1987), the social network view of actors with high betweenness but low in-degree values (such as project leaders with non-operational roles) is a reasonable predictor of the true underlying cognitive social structure. To validate the managers' subjective assessment, we then collected data from project management and human resources department records and developed matrices associating actors by interdependent task assignment, team authority and community structures, and actor work station locations (proximity). Based on theories of structural action 
TABLE 1 QAP Results and Significance Values

\begin{tabular}{lcc}
\hline Independent variable (predictor) model & Pearson's $r$ & $\%$ Higher $(p$ value $)$ \\
\hline 1. Proximity & 0.296 & 0.0023 \\
2. Authority/Community Structure & 0.656 & 0.0004 \\
3. Interdependent Task Assignment & 0.221 & 0.0140 \\
4. Proximity, Authority/Community, & 0.670 & 0.0001 \\
Task Assignment & & \\
\hline
\end{tabular}

(Burt, 1982) and physical proximity (Festinger, Schachter, \& Back, 1950; Korzenny \& Bauer, 1981; Monge et al., 1985; Oldham, Cummings, \& Zhou, 1995; Olson \& Olson, 2000; Kiesler \& Cummings, 2002; Monge \& Contractor, 2003), these matrices should have significant correlation with the observed social network. Irrespective of the correlation values (as long as they are non-trivial), the correlations of the independent matrices to the social network matrix must be among those with the highest possible levels of correlation in order to be considered "significant." To test the null hypothesis that there is no correlation between the affiliation/proximity matrices and the underlying social network, we used the quadratic assignment procedure (Hubert \& Schultz, 1976; Krackhardt, 1987) based on ten thousand Monte Carlo simulations. To address concerns of potential multicollinearity, we use the semi-partialling extension to the QAP method developed by Dekker, Krackhardt, and Snijders (2003).

As shown in Table 1, the QAP $p$-values for the proximity, authority/ community, and task assignment matrix predictors (Models 1-3) are statistically significant, with $p$ values of 0.0023 and 0.0004 , and 0.0140 , respectively. When the social network is regressed on all three predictor variables (Table 1, Model 4), the model is strongly statistically significant ${ }^{2}$ and exhibits a reasonably high Pearson's $r$. Thus, we reject the null hypothesis that the observed social network identified by the managers is not significantly correlated to the independent predictor matrices. This conclusion gives us reasonable assurance that the social network observed by the managers is free from significant

\footnotetext{
${ }^{2}$ In the multiple QAP regression (Model 4), the coefficients of the proximity and authority/community matrices were significant at $p=0.05$ and $p=0.001$, respectively. The task assignment matrix, however, did not have a statistically significant coefficient $(p=0.20)$ in the multiple regression. Since task assignment was significantly correlated with the social network matrix when considered standalone (Table 1, Model 3), the reduced significance in the combined regression indicates non-linearity in the multiple regression model.
} 


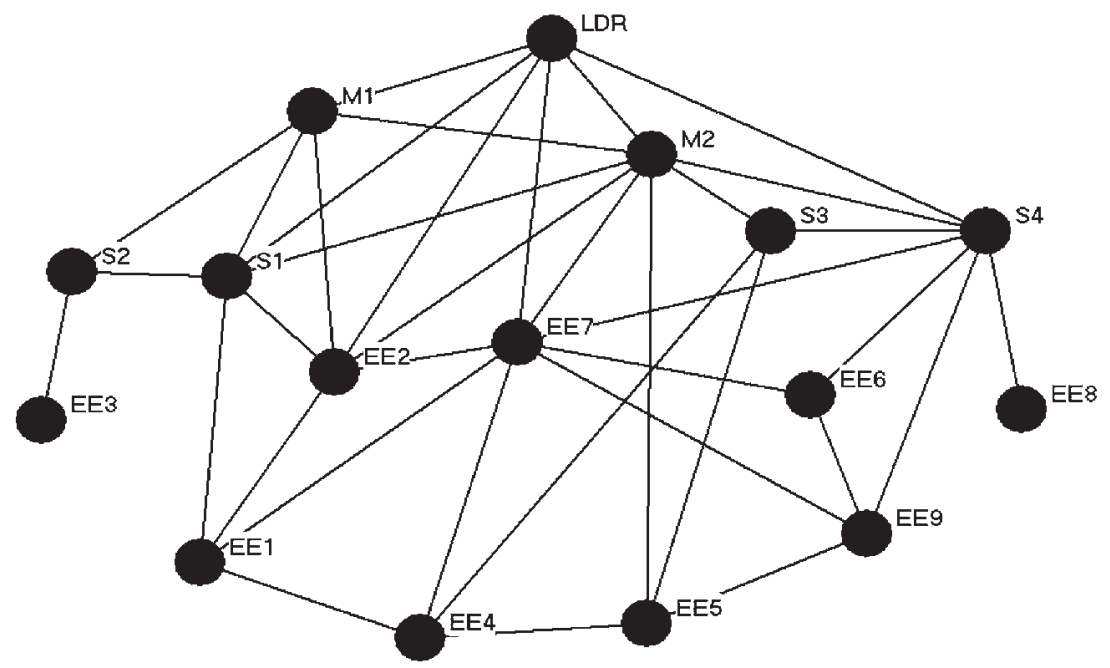

FIGURE 2 Team social network.

random or systematic error. The team's resultant network of social ties is shown in Figure 2.

After defining the social network, we identified skills, knowledge elements, and tasks of team members based on information provided by the company's human resources department and cross-validated by the technical division's knowledge management database and the team's formal project management plan (see Appendixes B and C).

\section{Theoretical Model}

After obtaining data on the software team, we developed a framework in which the data could be organized and evaluated computationally with respect to our investigation of individual actors' impact on team performance. Building on the organizational meta-network concept (Carley, 2002; Carley \& Hill, 2001; Krackhardt \& Carley, 1998), we defined the context of our analysis in terms of a linear algebraic meta-matrix relating the following primitives as depicted in Figure 3: people (actors), skills (including knowledge, experience and expertise), resources (physical or financial), and tasks.

For purposes of this paper, we only use sub-matrices, $N, S_{N}$, and $T_{N}$, all of which are assumed to represent fully connected, non-directional and dichotomous graphs. 


\begin{tabular}{|c|c|c|c|c|}
\hline & $\begin{array}{c}\text { People } \\
n \in\{1,2, \ldots, \hat{n}\}\end{array}$ & $\begin{array}{l}\text { Skill (Knowledge) } \\
\qquad s \in\{1,2, \ldots, \hat{s}\}\end{array}$ & $\begin{array}{c}\text { Resources } \\
r \in\{1,2, \ldots, \hat{r}\}\end{array}$ & $\begin{array}{c}\text { Tasks } \\
t \in\{1,2, \ldots, \hat{t}\}\end{array}$ \\
\hline $\begin{array}{l}\text { People } \\
n \in\{1,2, \ldots, \hat{n}\}\end{array}$ & $\begin{array}{l}\text { Social Network } \\
=N \equiv N_{\hat{n} \times \hat{n}} \\
\text { Who reports to whom } \\
\text { (authority network), } \\
\text { who communicates } \\
\text { with whom } \\
\text { (communication } \\
\text { network) }\end{array}$ & $\begin{array}{l}\text { Skill (Knowledge) } \\
\text { Network } \\
=S_{N} \equiv S_{\hat{n} \times \hat{s}} \\
\text { Who knows what or } \\
\text { has what skills }\end{array}$ & $\begin{array}{l}\text { Resource Access } \\
\text { Network } \\
=R_{N} \equiv R_{\hat{n} \times \hat{r}} \\
\text { Who has what (physical } \\
\text { or financial) resource }\end{array}$ & $\begin{array}{l}\text { Assignment Network } \\
=T_{N} \equiv T_{\hat{n} \times \hat{i}} \\
\text { Who does what }\end{array}$ \\
\hline $\begin{array}{l}\text { Skill } \\
\text { (Knowledge) } \\
s \in\{1,2, \ldots, \hat{s}\}\end{array}$ & & $\begin{array}{l}\text { Information } \\
\text { Network } \\
=S \equiv S_{\hat{\gamma} \times \hat{s}} \\
\text { What informs what } \\
\text { (what knowledge/skill } \\
\text { is linked to other } \\
\text { knowledge/skills) }\end{array}$ & $\begin{array}{l}\text { Resource Adequacy } \\
\text { Network } \\
=R_{S} \equiv R_{\hat{\delta} \times \hat{r}} \\
\text { What knowledge } \\
\text { requires } \text { what resource }\end{array}$ & $\begin{array}{l}\text { Needs Network } \\
=T_{S} \equiv T_{\hat{\mathrm{x}} \mathrm{x}} \\
\text { What knowledge is } \\
\text { needed to do that task }\end{array}$ \\
\hline $\begin{array}{l}\text { Resources } \\
r \in\{1,2, \ldots, \hat{r}\}\end{array}$ & & & $\begin{array}{l}\text { Substitution Network } \\
=R \equiv R_{\hat{r} \times \hat{r}} \\
\text { What resoures can be } \\
\text { substituted for which }\end{array}$ & $\begin{array}{l}\text { Requirements } \\
\text { Network } \\
=T_{R} \equiv T_{\hat{r} \times \hat{t}} \\
\text { What (physical and } \\
\text { financial) resources are } \\
\text { needed to do task }\end{array}$ \\
\hline $\begin{array}{l}\text { Tasks } \\
t \in\{1,2, \ldots, \hat{t}\}\end{array}$ & & & & $\begin{array}{l}\text { Precedence Network } \\
=T \equiv T_{\hat{i} \times \hat{\imath}} \\
\text { Which tasks must be } \\
\text { done before which }\end{array}$ \\
\hline
\end{tabular}

FIGURE 3 Generalized organization meta-matrix.

\section{Social Position Measures}

As proxies for comparing social network theory predictions of individual performance, we used traditional measures of degree centrality and betweenness centrality. Although the two indices may be correlated for some individuals (Bienenstock \& Bonacich, 2002), they were selected because of their now canonical status (Bavelas, 1948; Freeman, 1979), their familiarity and accepted use (Ahuja et al., 2003), and their relative ease of computation for the software team used in our analysis. Thus, we introduce a Degree Centrality Index $C I_{D}(n)$ based on classical definitions of degree centrality (Proctor \& Loomis, 1951; Freeman, 1979) as follows:

$$
C I_{D}(n)=\left(\frac{1}{C I_{D}^{\max }}\right) \frac{\sum_{j=1}^{\widehat{n}} N_{n j}}{\widehat{n}-1}
$$

Equation (1) states that the Degree Centrality Index $C I_{D}(n)$ for any actor $n$ is the sum of 1's across row $n$ of the social network matrix $N$ (actor $n$ 's raw "degree" measure), divided by $\widehat{n}-1$ and normalized by $1 / C I_{D}^{\max }$ (the maximum value of $C I_{D}(n) \forall n$ ). 
We similarly define a Betweenness Centrality Index $C I_{B}(n)$ (Anthonisse, 1971; Freeman, 1977; Wasserman \& Faust, 1994) as follows:

$$
C I_{B}(n)=\left(\frac{1}{C I_{B}^{\max }}\right) \frac{\sum_{j<n<k} \mathrm{~g}(j, n, k) / \mathrm{g}(j, k)}{[(\widehat{n}-1)(\widehat{n}-2) / 2]}
$$

In Equation (2), the numerator represents the betweenness of actor $n$ (that is, the number of geodesics, or "shortest paths," between $j$ and $k$ containing $n$, divided by the total number of geodesics between $j$ and $k$ ), which is then divided by the total number of pairs not including $n$ (to compute a raw betweenness value) and normalized by multiplying the raw value by $1 / C I_{B}^{\max }$.

\section{Knowledge-Based Measures}

As proxies for comparison of knowledge and resource-based theories with social network theory, we extended and operationalized theories introduced by Mechanic (1962) and Dubin (1957) by defining three knowledge-based measures. The first, building on concepts of Brass (1984), Hinings et al. (1974), and Dubin (1963) is the Task Exclusivity Index (TEI), defined as

$$
T E I_{n}=\frac{1}{T E I^{\max }} \sum_{t=1}^{\widehat{t}} \alpha_{t} T_{N_{n t}} e^{\left(1-\bar{T}_{N_{t}}\right)}
$$

where $\bar{T}_{N_{t}}=\sum_{n=1}^{\widehat{n}} \frac{1}{\beta_{n}} T_{N_{n t}}$ and $T E I^{\text {max }}$ is the largest observed value of $T E I_{i}$. Parameters $\alpha_{t}$ and $\beta_{n}$ are weighting factors for each task $t$ and individual $n$, respectively, where $\alpha_{t}>0$ and $0<\beta_{n} \leq 1$.

Brass (1984) recognized the importance of workflow criticality and proposed his conceptually similar "Transaction Alternatives" metric, which computes the number of different actors who can perform precedent and post-hoc tasks for each reciprocal task. Actors who exclusively perform such tasks are deemed more critical. Other than the fact that Brass's measure derives from survey and interview data, the main difference between our proposed task measure and Brass's is that his focuses primarily on such reciprocal tasks while ours generalizes to the entire set of task interdependencies as defined by Thompson (1967) and incorporates the inverse proportionality relationship between task uniqueness and task criticality (Dubin, 1963).

The TEI in Equation (3) essentially measures the extent to which each actor is the only one who can do certain tasks. The TEI is weighted toward unity for individuals who have one or more unique 
task assignments, with values associated with individuals with fewer unique tasks declining exponentially. A potential drawback of the TEI approach could arise if the task assignment matrix $\mathrm{T}_{N}$ is defined at such a granular level that every task is assigned to only one person, essentially reducing $\mathrm{T}_{N}$ to a unit matrix. Here, grouping of similar tasks may be necessary to obtain a meaningful assignment matrix.

Consistent with human capital measurement theory (Boudreau, 1997), our second measure, the Knowledge Exclusivity Index (KEI), builds similarly on the knowledge dimension:

$$
K E I_{n}=\frac{1}{K E I^{\max }} \sum_{s=1}^{\widehat{s}} \alpha_{s} S_{N_{n s}} e^{\left(1-\bar{S}_{N_{s}}\right)}
$$

where $\bar{S}_{N_{s}}=\sum_{n=1}^{\widehat{n}} \frac{1}{\beta_{n}} S_{N_{n s}} ; K E I^{\text {max }}$ is the largest observed value of $K E I_{n}$; and $\alpha_{s}$ is a weighting factor for skill $s$. As in the TEI (Equation 3), the KEI measures the extent to which each actor is the only one who possesses certain skills, knowledge, or expertise. Also similar to the TEI, the KEI is weighted toward unity for individuals who possess one or more unique skill or knowledge elements, with values associated with individuals with fewer unique skills declining exponentially. To avoid issues of granularity similar to those of the TEI, grouping of similar skills may be necessary to obtain a meaningful knowledge matrix $S_{N}$.

Extending Brass's (1984) and Hickson et al.'s (1974) notion of access exclusivity and Blau and Alba's (1982) suggestion that "communication access" to key individuals increases actor criticality, our next proposed measure is the Knowledge Access Index (KAI). Unlike the TEI and KEI, which range between 0 and 1, the KAI is binary and is defined as follows:

Definition: $K A I_{n}=1$ iff $\exists$ skill $s$ for individual $n \mid \bar{S}_{N_{s}}=1$ and $\bar{N}_{n}=\sum_{j=1}^{n} N_{n j}=1 ; K A I_{i}=0$ otherwise. Furthermore, if $K A I_{n}=1$, then $K A I_{j}=1$ for the value of $j$ where $N_{n j}=1$.

The KAI calculation first identifies an actor who is the only actor possessing certain knowledge. If this actor is tied to only one other actor in the social network matrix $N$, then both the person with the unique knowledge (or skill or expertise) and the actor to whom this person is uniquely tied are considered potentially critical employees and are assigned KAI values of 1 .

As a proxy for synthesizing social network and resource dependency theories, our final proposed measure is a Composite Criticality Measure (CCM), defined as

$$
C C M_{n} \equiv f\left(C I_{D}(n)\right)+f\left(C I_{B}(n)\right)+f\left(T E I_{n}\right)+f\left(K E I_{n}\right)+f\left(K A I_{n}\right)
$$




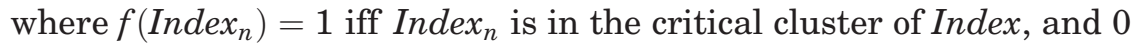
otherwise. We determine critical clusters based on agglomerative hierarchical clustering analysis.

Consistent with social network and resource dependency theories, we assume that a higher value for any index indicates an actor with a higher level of criticality with respect to that index. In addition, without loss of generality, we set all $\alpha$ and $\beta$ parameters equal to 1 .

\section{Simulation Model}

In addition to the meta-matrix framework and the measures of social position and knowledge, another important component of our approach involves establishing a benchmark for comparing actors' criticality based on the proposed measures. The benchmark we apply is performance impact as defined through successive simulations of the software development team with and without each actor. Accordingly, we define a critical human capital asset as an individual whose absence or loss will result in a greater decrease in team performance relative to other individuals on the same team. Since it is virtually impossible to obtain empirical data examining team performance with and without each actor, simulation proves to be an excellent means of estimating baseline performance values for each individual on the team.

The computer simulation model we employ is an adaptation of the multi-agent Construct model originally developed by Carley and Kaufer (Carley, 1990, 1991; Carley, Lee, \& Krackhardt, 2001; Kaufer \& Carley, 1993) and validated in studies by Carley and Krackhardt (1996), Carley and Hill (2001), and Schreiber and Carley (2004). The current version of Construct (complete open source shareware available publicly) simulates organizations in terms of tasks, knowledge, and interactions associated with multiple groups and agents. Our modified version permits the selective removal of any specific actor at any time in the simulation horizon, enabling researchers to evaluate team performance with and without one or more actors. The team's performance in Construct is determined by each agent's participation in a binary-choice task in which the team must decide for a binary string whether there are more 1's or 0's in the string. The task is distributed in such a way that no individual actor or sub-group can "see" and act on the entire string, with the parts of the task that an actor sees being dependent on what pieces of task knowledge and skills the actor has. Thus, in our simulation, such decisions act as proxies for team objectives, which, in the case of the software team, represent stylized sub-tasks in IT project management and implementation. Performance is calculated as team accuracy, or the 
fraction of tasks on which the team correctly acts with respect to the full binary-choice task presented. The size of the binary-choice task is the same as the total number of skills/tasks in the knowledge matrix $S_{N}$, and in each time period of the simulation, the organization is presented with 25 such stylized tasks. Thus, in terms of the software team simulated in our study, every actor participates in the team's activity each period to the extent of the actor's task knowledge and skill. We make no attempt to represent details of "software coding" in our model, since the task, knowledge, and skill links capture each actor's incremental contribution to team performance.

In addition to defining the communication and knowledge networks, we modeled the team's structure and roles, dividing the software team into three hierarchical levels of three managers (a Project Leader plus two managers), four supervisors, and nine employees. Construct enables actors to incorporate transactive memory (TM) (Liang et al., 1995), and although we assumed an average TM level of $50 \%$, we found the simulations to be insensitive to TM levels (varying from $0 \%$ to $100 \%$ ), suggesting that the team was small enough and task-dependent actors were connected well enough to minimize the significance of transactive memory influences. Another multi-agent parameter of Construct allows actors to interact with varying degrees of homophilistic (relative similarity) versus information seeking behavior. Although we assumed an equal balance of each type of interaction (50\% homophily-based and 50\% information seeking-based) for our base case, we found no sensitivity to variations ranging from complete homophily to complete information seeking, suggesting that both homophilistic and information seeking behaviors of team members were primarily aligned with tasks for which they or others similarly tasked were trained and had experience (Hinds et al., 2000). We additionally assumed (realistically in the case of the software team we studied) that all agents were fully engaged in their respective tasks at all times, thus there were no slack resources.

\section{Research Methodology}

As the first step in our research approach, we determined which members of the software team were critical employees based on their performance impact. We accomplished this by running a base case simulation with all employees and then deleting each actor in turn in 16 subsequent simulations. Based on the incremental difference in performance associated with the removal of each actor, we defined a benchmark measure of each actor's relative criticality as the absolute value of the mean percentage decrease in team performance 
resulting from the deletion of that actor, ceteris paribus. This experimental approach is consistent with Price's (1977) and Argote's (1999) suggestion that organizational effectiveness is positively related to the performance levels of individuals in the organization. We thus theorized, and results confirmed, that performance will always decline upon removal of any non-slack actor. To confirm effect sizes, we conducted statistical testing on the performance differences to examine significance of actor impacts and performed clustering analysis to identify the baseline group of "critical" actors. As an interim check of face validity, we interviewed the project manager of the software team to confirm that the model's resultant identification of critical actors was consistent with management intuition and direct knowledge. Then, for all actors, we calculated the traditional and knowledge-based measures and compared them to the base case estimates using a hierarchical clustering technique. Finally, we evaluated our propositions based on receiver operating characteristic (ROC) curve analysis.

\section{RESULTS}

\section{Determination of Critical Human Asset Group}

For the base case (that is, for the complete team of 16 people) and for each of the 16 cases representing incremental removal of an actor on the software team, we executed 100 Monte Carlo simulations. Besides establishing a baseline for further comparison, this result confirms Kiesler et al.'s (1994) suggestion that each actor on a well-designed team will have measurable positive impact on the team's overall performance. Each simulation spanned 250 time periods, with a two-period lag at the beginning of each run before removal of any particular actor. The removed actor was not included on the team for the remaining 248 time periods.

In Figure 4, we show the actors ranked by performance impact and grouped into two clusters based on a hierarchical similarity analysis that minimizes average Euclidian distance differences between clusters (Sokal \& Michener, 1958). ${ }^{3}$ As might be expected given the relatively

\footnotetext{
${ }^{3}$ The hierarchical clustering technique used throughout the paper is based on average linkage updating of distance between clusters (Sokal and Michener, 1958). The distance between the coordinates of each actor (as determined by actors' $x$ and $y$ values of the metric being clustered, such as $x=$ degree centrality with $y=$ performance index) is calculated as Euclidean distance. Then, the distance $D_{c k}$ between clusters $c$ and $k$ is computed as

$$
D_{c k}=T_{c k} /\left(n_{c} * n_{k}\right)
$$

where $T_{c k}$ equals the sum of all pairwise distances between actors in cluster $c$ and cluster $k$, and $n_{c}$ and $n_{k}$ are the sizes of clusters $c$ and $k$ respectively. At each stage of clustering algorithm, the clusters for which $D_{c k}$ is the minimum are merged.
} 


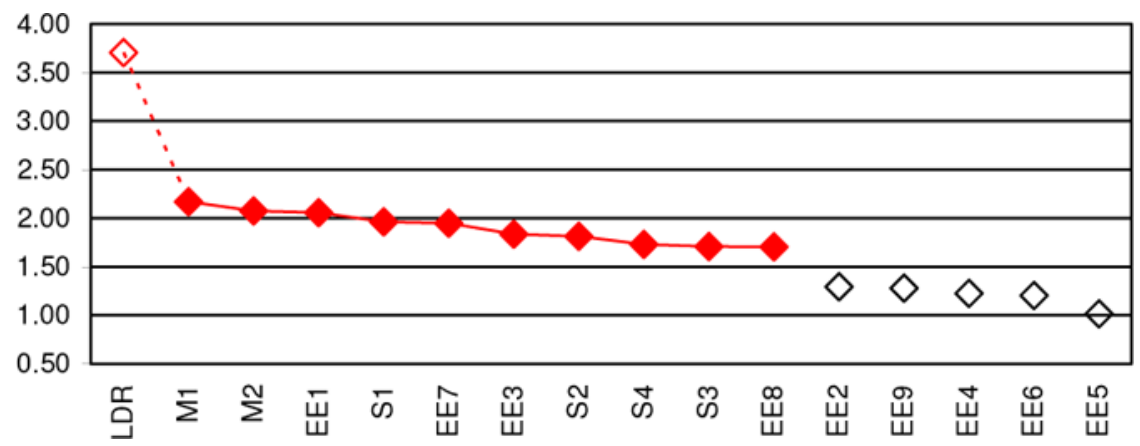

FIGURE 4 Results of multi-agent simulation and cluster analysis showing cluster of eleven "critical" employees.

high performance impact shown for the Leader, the initial clustering analysis placed this actor in a distinct cluster. Since using that cluster alone as a definition of the baseline "critical employees" is trivial, we include the Leader and all employees in the second cluster as our "critical" group. Although specifying 11 out of 16 people on a team as "critical employees" may seem high, it is consistent with our proposed definition of criticality and is intuitively acceptable given the small size of the test team and the typically high degree of specialization on software engineering teams (Carley et al., 1993). An interim interview with the project manager also confirmed face validity of the results.

It is clear from Table 2 and Figure 4 that different individuals have different impacts on the team's performance, contradicting Bienenstock \& Bonacich's (2002) contention that removal of any single individual results in the same impact on team performance and confirming theories that such removals are actually deleterious (Price, 1977; Mowday, Porter, \& Steers, 1982).

As Table 3 confirms, the differences in impacts are generally significant. The average effect size $d$ (defined as $M_{\text {Base }}-M_{n} / S D$ ) is 0.74 , with a range from 0.39 to 2.32 , all with moderate to high levels of statistical power (Cohen, 1988), indicating that all performance decrements are significant. The $z$ values for a hierarchical, two-tailed Wilcoxon signed rank test of the difference in performance distributions between each actor and the next-lower ranked actor show significance at $p<0.05$ for 11 out of the 15 differences (see Table 3). Moreover, the values exhibiting the least significance $(0.0910<p<0.7114)$ are consistent with the results of our clustering analysis (Figure 4 ). 
TABLE 2 Performance Results and Significance Based on 10,000 Simulations $\left(\mathrm{df}=494,{ }^{*} \mathrm{p}<.001\right)$

\begin{tabular}{lccccc}
\hline & $M$ & $S D$ & $M_{\text {Base }}-M_{n}$ & $t$-value & $\%$ Impact \\
\hline LDR & 63.800 & 1.056 & 2.455 & $17.651^{*}$ & 3.705 \\
M1 & 64.817 & 1.649 & 1.438 & $8.952^{*}$ & 2.170 \\
M2 & 64.880 & 1.683 & 1.375 & $8.483^{*}$ & 2.075 \\
S1 & 64.954 & 1.791 & 1.301 & $7.804^{*}$ & 1.963 \\
S2 & 65.054 & 1.725 & 1.201 & $7.331^{*}$ & 1.813 \\
S3 & 65.123 & 1.807 & 1.132 & $6.761^{*}$ & 1.708 \\
S4 & 65.109 & 1.790 & 1.146 & $6.878^{*}$ & 1.730 \\
EE1 & 64.891 & 1.769 & 1.364 & $8.228^{*}$ & 2.058 \\
EE2 & 65.397 & 1.736 & 0.858 & $5.221^{*}$ & 1.295 \\
EE3 & 65.038 & 1.712 & 1.217 & $7.456^{*}$ & 1.838 \\
EE4 & 65.443 & 1.793 & 0.812 & $4.870^{*}$ & 1.226 \\
EE5 & 65.583 & 1.730 & 0.672 & $4.099^{*}$ & 1.015 \\
EE6 & 65.458 & 1.797 & 0.797 & $4.776^{*}$ & 1.203 \\
EE7 & 64.963 & 1.725 & 1.292 & $7.884^{*}$ & 1.949 \\
EE8 & 65.126 & 1.788 & 1.129 & $6.780^{*}$ & 1.704 \\
EE9 & 65.407 & 1.733 & 0.848 & $5.163^{*}$ & 1.279 \\
\hline
\end{tabular}

\section{Computation and Comparison of Measures}

Table 4 summarizes raw calculations of all social position and knowledge-based indexes, and Figure 5 shows a relative comparison of normalized values for each actor on the software team.

TABLE 3 Results of Wilcoxon Test Showing Significance of Differences between Actors' Performance Impacts $(\mathrm{df}=248)$

\begin{tabular}{rcccc}
\hline Rank & Actor & \% Impact & Wilcoxon $z$ & $p$ \\
\hline 1 & LDR & 3.705 & - & - \\
2 & M1 & 2.170 & -13.330 & $<.0001$ \\
3 & M2 & 2.075 & -5.999 & $<.0001$ \\
4 & EE1 & 2.058 & -0.370 & $<.7114$ \\
5 & S1 & 1.963 & -5.210 & $<.0001$ \\
6 & EE7 & 1.949 & -1.600 & $<.1096$ \\
7 & EE3 & 1.838 & -9.610 & $<.0001$ \\
8 & S2 & 1.813 & -2.040 & $<.0414$ \\
9 & S4 & 1.730 & -5.370 & $<.0001$ \\
10 & S3 & 1.708 & -2.930 & $<.0034$ \\
11 & EE8 & 1.704 & -0.590 & $<.5552$ \\
12 & EE2 & 1.295 & -13.490 & $<.0001$ \\
13 & EE9 & 1.279 & -1.690 & $<.0910$ \\
14 & EE4 & 1.226 & -3.000 & $<.0027$ \\
15 & EE6 & 1.203 & -2.110 & $<.0349$ \\
16 & EE5 & 1.015 & -7.760 & $<.0001$ \\
\hline
\end{tabular}


TABLE 4 Computations of Measures

\begin{tabular}{lcccccc}
\hline & $C I_{D}(n)$ & $C I_{B}(n)$ & $T E I_{n}$ & $K E I_{n}$ & $K A I_{n}$ & $C C M_{n}$ \\
\hline LDR & 0.750 & 0.387 & 0.730 & 0.817 & 0 & 3 \\
M1 & 0.625 & 0.433 & 0.789 & 0.747 & 0 & 4 \\
M2 & 1.000 & 1.000 & 1.000 & 1.000 & 0 & 4 \\
S1 & 0.750 & 0.697 & 0.769 & 0.532 & 0 & 4 \\
S2 & 0.375 & 0.625 & 0.136 & 0.110 & 1 & 2 \\
S3 & 0.500 & 0.957 & 0.136 & 0.044 & 0 & 1 \\
S4 & 0.875 & 0.932 & 0.558 & 0.554 & 0 & 4 \\
EE1 & 0.500 & 0.222 & 0.616 & 0.036 & 0 & 1 \\
EE2 & 0.750 & 0.177 & 0.127 & 0.034 & 0 & 1 \\
EE3 & 0.125 & 0.000 & 0.232 & 0.682 & 1 & 2 \\
EE4 & 0.500 & 0.119 & 0.260 & 0.015 & 0 & 0 \\
EE5 & 0.500 & 0.108 & 0.050 & 0.034 & 0 & 0 \\
EE6 & 0.375 & 0.000 & 0.096 & 0.252 & 0 & 0 \\
EE7 & 1.000 & 0.831 & 0.585 & 0.001 & 0 & 3 \\
EE8 & 0.125 & 0.000 & 0.679 & 0.034 & 0 & 1 \\
EE9 & 0.500 & 0.893 & 0.029 & 0.036 & 0 & 1 \\
\hline
\end{tabular}

Figure 5 reveals results that are non-linear across measures but consistent in many respects with expectations based on traditional social network analysis. Despite a few exceptions (example, LDR, S3, and EE2), degree and betweenness measures appear to be correlated. In addition, the leaders of the team (LDR, M1, M2, and S1 through S4) have generally higher degree and betweenness centrality measures compared to the employee group (EE1 through EE9). Notable exceptions are employees EE7 and EE9, both of whom exhibit centrality measures similar to the leadership group. Upon further inspection, however, Figure 5 indicates clear inconsistencies between

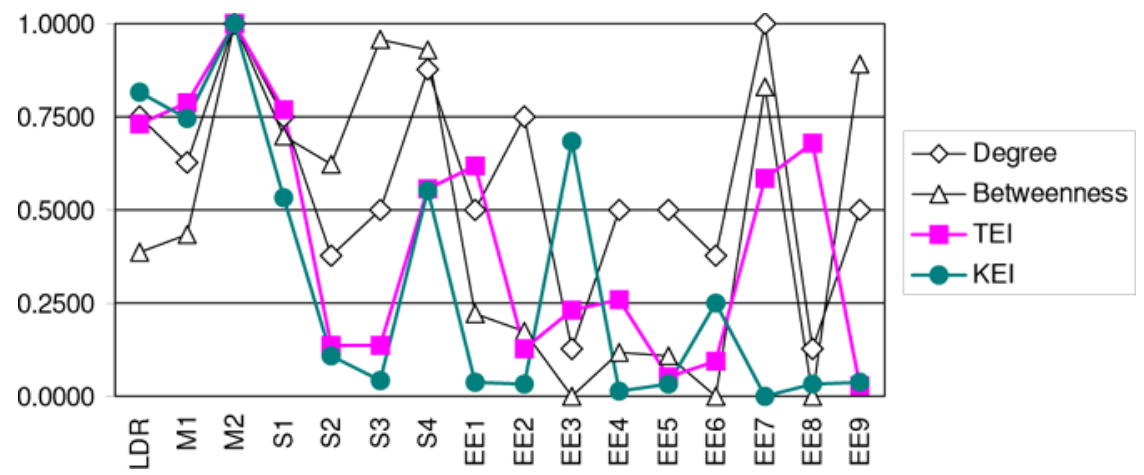

FIGURE 5 Measures results for all team members. 
social position and knowledge-based measures. For example, while employees EE1, EE3, and EE8 have relatively low degree and betweenness centrality measures, they score among the highest in terms of task exclusivity for EE1 and EE8 and in terms of knowledge exclusivity for EE3. While not always the case, actors with low centrality measures may be more introverted "experts" (Burt, 1992; Prietula \& Simon, 1989), so the fact that EE3 and EE8 are near-isolates (see Figure 2) is not inconsistent with such tendencies.

\section{Evaluation of Propositions}

Figures 6 a through $6 \mathrm{~d}$ reveal graphically the results of agglomerative hierarchical clustering analysis performed on the degree, betweenness, $T E I_{n}$, and $K E I_{n}$ measures. We did not include graphs for the

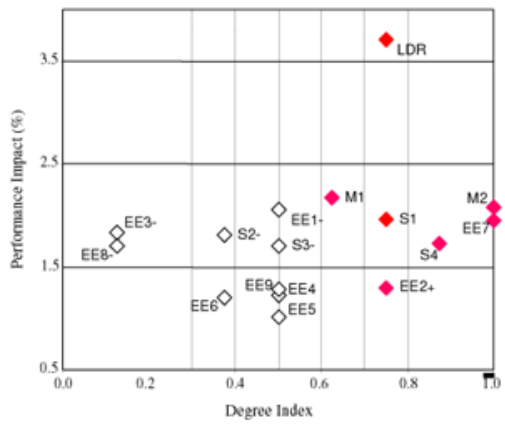

(a)

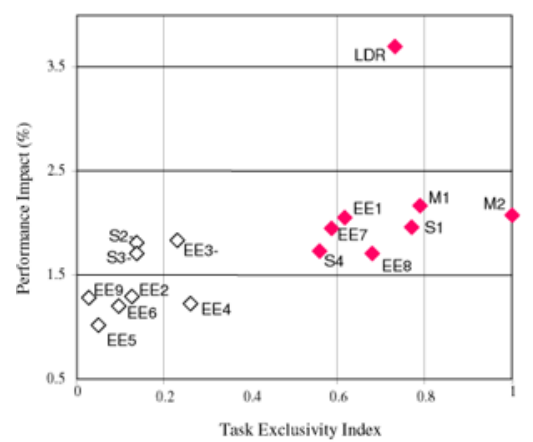

(c)

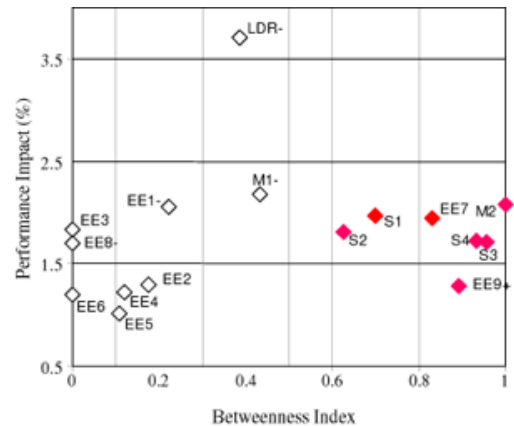

(b)

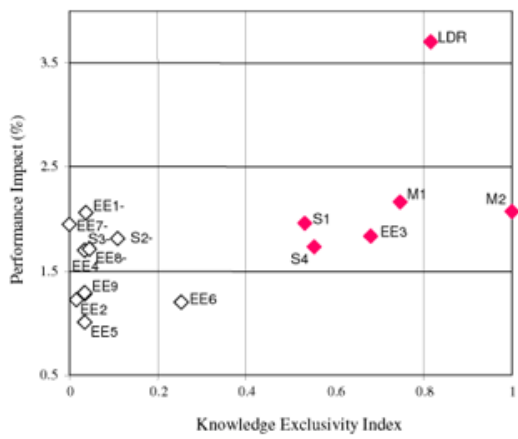

(d)

FIGURE 6 Results of alustering analysis for (a) degree, (b) betweenness, (c) TEI and (d) KEI. Critical actors are shaded, with + or - indicating false positive/ negative. (a) Degree critical actors, (b) Betweenness critical actors, (c) TEI critical actors, (d) KEI critical actors. 
TABLE 5 Critical Employee Groups as Determined by Clustering Analysis of Index Results (- or + Indicates False Negative/Positive)

\begin{tabular}{|c|c|c|c|c|c|c|c|c|c|}
\hline & Base case & $C I_{D}(n)$ & $C I_{B}(n)$ & $T E I_{n}$ & $K E I_{n}$ & $K A I_{n}$ & $C C M_{n}$ & $\begin{array}{c}\text { Social } \\
\text { position } \\
\text { heuristic }\end{array}$ & $\begin{array}{c}\text { Knowledge- } \\
\text { based } \\
\text { heuristic }\end{array}$ \\
\hline LDR & $\mathrm{C}$ & $\mathrm{C}$ & - & $\mathrm{C}$ & $\mathrm{C}$ & - & $\mathrm{C}$ & $\mathrm{C}$ & $\mathrm{C}$ \\
\hline M1 & $\mathrm{C}$ & $\mathrm{C}$ & - & $\mathrm{C}$ & $\mathrm{C}$ & - & $\mathrm{C}$ & $\mathrm{C}$ & $\mathrm{C}$ \\
\hline M2 & $\mathrm{C}$ & $\mathrm{C}$ & $\mathrm{C}$ & $\mathrm{C}$ & $\mathrm{C}$ & - & $\mathrm{C}$ & $\mathrm{C}$ & $\mathrm{C}$ \\
\hline $\mathrm{S} 1$ & $\mathrm{C}$ & $\mathrm{C}$ & $\mathrm{C}$ & $\mathrm{C}$ & $\mathrm{C}$ & - & $\mathrm{C}$ & $\mathrm{C}$ & $\mathrm{C}$ \\
\hline $\mathrm{S} 2$ & $\mathrm{C}$ & - & $\mathrm{C}$ & - & - & $\mathrm{C}$ & $\mathrm{C}$ & $\mathrm{C}$ & $\mathrm{C}$ \\
\hline S3 & $\mathrm{C}$ & - & $\mathrm{C}$ & - & - & - & - & $\mathrm{C}$ & - \\
\hline $\mathrm{S} 4$ & $\mathrm{C}$ & $\mathrm{C}$ & $\mathrm{C}$ & $\mathrm{C}$ & $\mathrm{C}$ & - & $\mathrm{C}$ & $\mathrm{C}$ & $\mathrm{C}$ \\
\hline EE1 & $\mathrm{C}$ & - & - & $\mathrm{C}$ & - & - & - & - & $\mathrm{C}$ \\
\hline EE2 & & $\mathrm{C}+$ & & & & & & $\mathrm{C}+$ & \\
\hline EE3 & $\mathrm{C}$ & - & - & - & $\mathrm{C}$ & $\mathrm{C}$ & $\mathrm{C}$ & - & $\mathrm{C}$ \\
\hline \multicolumn{10}{|l|}{ EE4 } \\
\hline \multicolumn{10}{|l|}{ EE5 } \\
\hline \multicolumn{10}{|l|}{ EE6 } \\
\hline EE7 & C & C & $\mathrm{C}$ & C & - & - & C & C & C \\
\hline EE8 & C & - & - & C & - & - & - & - & C \\
\hline EE9 & & & $\mathrm{C}+$ & & & & & $\mathrm{C}+$ & \\
\hline
\end{tabular}

$T E I_{n}$ and $K E I_{n}$ measures, but their clustering results are summarized in Table 5 along with all other measures tested. These graphs indicate that there is a "core" of three critical actors - M2, S1, and S4 - identified by all four indexes. However, as we hypothesized, the traditional social position measures of degree and betweenness identify certain actors who are not deemed critical in our simulation benchmark. In one case, for example, the social position measures correctly identify actor S3 as critical when the knowledge-based measures do not. In other instances (example, EE2 and EE9), the social position measures ascribe criticality erroneously.

In Table 5, rather than using numerical values, we indicate criticality of an actor for any given index with the letter "C." In the Social Position Heuristic and Knowledge-Based Heuristic columns, we provide heuristic measures denoting an individual as critical (C) if the union of the respective social position (degree and betweenness centrality) or knowledge-based (task, knowledge, and knowledge access exclusivity) measures yields a C. False negatives and false positives versus the base case for each index are flagged with a " - " or "+" sign, respectively. For example, the "C+" for employee EE2's degree index, $C I_{D}(n)$, indicates that the degree index measure identified EE2 as critical, but the "+" indicates that this result was a false positive. Likewise, the 
“-" shown for employee M1's betweenness index, $C I_{B}(n)$, indicates that M1 was not identified as critical according to the cluster analysis of betweenness results, but the " - " means this is a false negative (i.e., M1 should have been identified as critical).

Based on these results, we can now examine in detail our research propositions. With respect to $\mathrm{P} 1 \mathrm{a}$ and $\mathrm{P} 1 \mathrm{~b}$, it is clear they cannot be

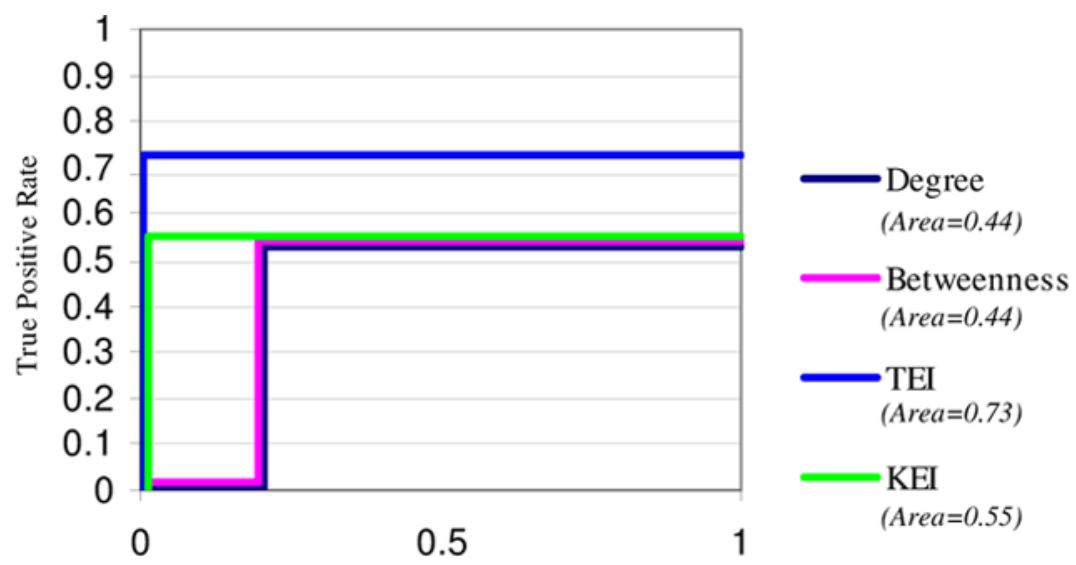

False Positive Rate

(a)

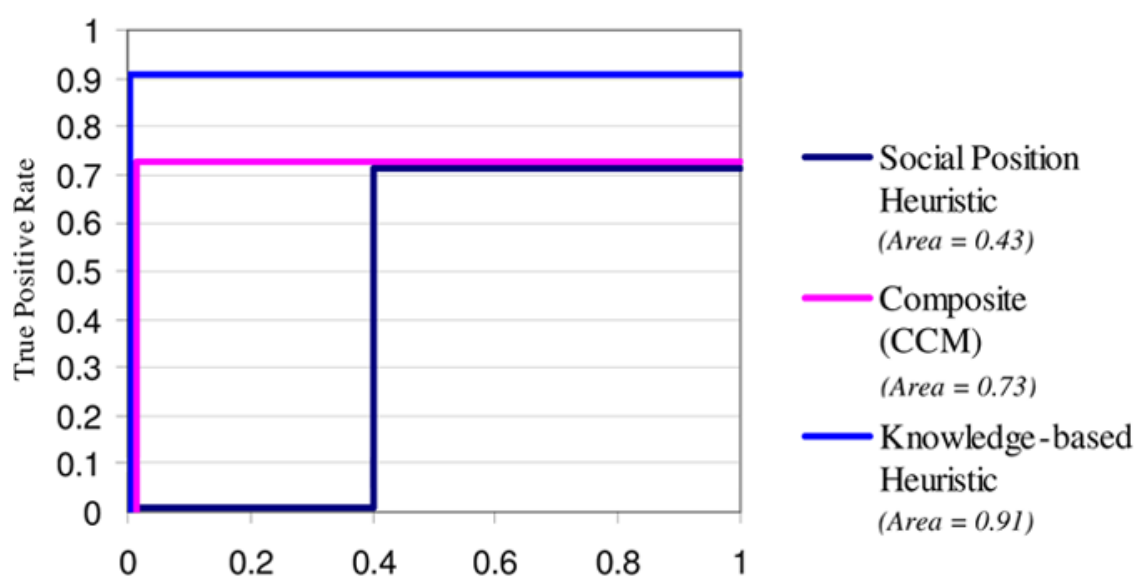

False Positive Rate

(b)

FIGURE 7 (a) ROC curves comparing degree, betweenness, TEI and KEI measures. (b) ROC curves comparing composite, social position and knowledgebased heuristic measures. 
rejected, as indexes $C I_{D}(n)$ and $C I_{B}(n)$ as well as the $C I_{D}(n) \cup C I_{B}(n)$ relation ("Social Position Heuristic") all display significant instances of false negatives (affirming P1a) and false positives (affirming P1b). As shown in Figures $7 \mathrm{a}$ and $7 \mathrm{~b}$, the area under the ROC curves for the degree $($ area $=0.44)$, betweenness $($ area $=0.44)$, and social position heuristics (area $=0.43$ ) are all unacceptably low. Thus, we accept propositions $\mathrm{P} 1 \mathrm{a}$ and $\mathrm{P} 1 \mathrm{~b}$.

With respect to P2, Figure 7a shows that the ROC results for task exclusivity (area under $T E I_{n}$ ROC curve $=0.73$ ) and knowledge exclusivity (area under $K E I_{n}$ ROC curve $=0.55$ ) fare appreciably better than those of social network measures, but these measures still do not exhibit acceptably robust ROC levels (i.e., area under curve $>0.80$ ) when used alone. However, when used in combination, the $T E I_{n}, K E I_{n}$, and $K A I_{n}$ identify EE1, EE3, and EE8 as critical, and those instances alone are enough to prove non-constructively that knowledge elements, particularly as represented by task and knowledge exclusivity, can be used to identify critical human assets that social network theory applied in isolation may overlook. As the ROC curve analysis shows in Figure 7b, the "knowledge-based heuristic" measure, where an individual is assigned "critical" status if $T E I_{n} \cup K E I_{n} \cup K A I_{n}=$ "C", exhibited the highest degree of discriminatory power and provides support for proposition 2 .

Finally, we do not find support for our proposition that a synthesis of theories, represented by the composite measure, $C C M_{n}$, can be used to reliably identify all critical human assets, since we find unacceptable levels of false negatives (S3, EE1 and EE8) and only a fair rating with respect to the ROC curves in Figure 7b (area under $C C M_{n}$ ROC curve $=0.73$ ). This result is not altogether unexpected, since the composite measure results reflect the unfortunately high number of false negatives indicated by the social network measures.

\section{DISCUSSION AND CONTRIBUTIONS}

Our results confirm that social network theory is reasonably robust in predicting human capital performance but may present deficiencies when task assignment and knowledge are taken into account. We hypothesized that resource dependency theory may satisfy those deficiencies and used task- and knowledge-based measures to show how a resource-based view substantially improves the robustness of predicting criticality of human assets based on their relative impact on team performance. Notwithstanding the improvements offered by knowledge-based theories, we find that no single measure or class of measures identifies all critical human capital, but that a heuristic 
application of knowledge-based measures results in the highest overall accuracy. As Figure 7 shows, the Knowledge-Based Heuristic approach using our task- and knowledge-based measures alone results in a significantly more satisfactory ROC curve than any of the other measures (area under curve $=.91$, compared with other values ranging from 0.43 to 0.73 ).

Hence we believe the major contribution of our work is in providing empirical evidence that the impact of individuals on team performance is more closely associated with knowledge and task dimensions than with social network structure. Our work also strengthens the tenets of resource dependency theory by providing new motivation for increased attention on the value of managing the knowledge and skill bases of individuals in organizations.

Finally, our work contributes to the growing body of literature on social network theory, human capital measurement theory, and dynamic organization network theory. Traditional social network theory is limited not only in its focus primarily on socio-metric aspects of organizations, but also in its lack of practical ability to incorporate the dynamic nature of those aspects. The survey-based data employed in social network analyses are difficult to obtain and even more difficult or perhaps impossible to maintain longitudinally. The methods proposed in this paper can operationalize theory using data that may be more easily obtained dynamically, longitudinally and noninvasively from existing organization information systems such as ERP systems, human resource information systems, project management databases, and knowledge databases.

With respect to potential shortcomings of social network theory, it bears emphasizing that even though the social position measures used in our study fared less convincingly compared to knowledge-based measures, we do not believe this means that centrality measures are not useful or valid. Traditional social network analysis focuses on small numbers of linkages (such as friendship and advice) between actors at only one point in time (Carley, 2004). Moreover, such analyses assume perfect or near perfect information. Despite their limitations as revealed in our analysis, such traditional centrality-based approaches can clearly be richer in social dimensions that may have important organizational implications in their own right, suggesting that a synthesis of social network measures, such as information centrality (Stephenson \& Zelen, 1989) and continuing flow (Bolland, 1988), with resource-based approaches may provide a stronger combination of qualitative and quantitative insight on criticality of team actors. The implications are consistent with Wasserman and Faust's (1994) observation that "one should not use any single centrality 
measure [since] each has its virtues and utility." We extend this admonition to knowledge-based measures as well.

Although our proposed integration of theory has intuitive and empirical appeal, we also recognize potential limitations to its wider application. For example, the accuracy of knowledge-based predictions is based on the premise that key tasks and related knowledge elements are well understood for all actors in the organization. In reality, these factors may not be understood at all, and depending on each individual's knowledge-sharing characteristics and the presence of socially connected versus isolated members, certain knowledge elements may not become diffused in the group over time (Thomas-Hunt et al., 2003). Even though we believe the task and knowledge elements of our meta-matrix framework contributes to improving such understanding, assembling data could be just as daunting and costly as social network analysis.

Another issue that may limit application of our theory is scalability to teams that are larger or more diverse than the software team we analyzed in our study. In particular, use of a single team as the central source of empirical data may constrain generalizability. However, the study incorporated essentially 17 teams by using simulation to analyze the base case view of the full 16-member team along with 16 "experimental" teams, each with one of the 16 original members missing. Scalability is affected not only by the size and number of teams but also by the intensity of ties, level of decentralization, and number of generalists versus specialists in the organization. Additional research should explore just how "complete" the information needs to be before results can be accepted with reasonable confidence. With respect to accuracy of the measures, we believe that more research is also needed on the effects of the $\alpha$ and $\beta$ parameters, since they may provide a means of increasing sensitivity. We suspect, however, that any increase in sensitivity may come only at the expense of specificity if the parameters are set a priori based on traditional social network analysis or management intuition.

\section{CONCLUSION}

In summary, many dynamic facets of human capital, ranging from power and social relations to attributes related to tasks, knowledge, and resources, are crucial in understanding the relative contribution of individuals to team performance. Our work shows that a resource-based view focusing on knowledge provides the most robust link between individual performance and team performance. Our knowledge and task-based perspectives confirm empirically that key 
contributors may not always be obvious actors such as leaders and managers, but rather those "everyday actors who offer something absolutely unique, with a special history in every respect" (Barnard, 1938). In understanding and managing team performance, the knowledge and skill possessed by those "everyday actors" may just represent the most critical human capital of all.

\section{REFERENCES}

Ahuja, M., Galletta, D., \& Carley, K. (2003). Individual centrality and performance in virtual R\&D groups: An empirical study. Management Science, 49(1), 21-38.

Anthonisse, J. (1971). The Rush in a Graph, Amsterdam: Mathematische Centrum.

Argote, L. (1999). Organizational Learning: Creating, Retaining and Transferring Knowledge, Norwell, MA: Kluwer.

Barnard, C. I. (1938). The Functions of the Executive, Cambridge, MA: Harvard University Press.

Bavelas, A. (1948). A mathematical model for group structure. Human Organization, 7, 16-30.

Benbasat, I., Goldstein, D., \& Mead, M. (1987). The case research strategy in studies of information systems. MIS Quarterly, 11(3), 369-386.

Bienenstock, E. \& Bonacich, P. (2002). Balancing efficiency and vulnerability in social networks. (Working paper).

Blau, J. \& Alba, R. (1982). Empowering nets of participation. Administrative Science Quarterly, 27, 363-379.

Bolland, J. (1988). Sorting out centrality: An analysis of the performance of four centrality models in real and simulated networks. Social Networks, 10, 233-253.

Bonoma, T. (1985). Case research in marketing: Opportunities, problems and a process. Journal of Marketing Research, 22(2), 199-208.

Boudreau, J. \& Ramstad, P. (1997). Measuring intellectual capital: Learning from financial history. Human Resource Management, 36(3), 343-356.

Brass, D. (1984). Being in the right place: A structural analysis of individual influence in an organization. Administrative Science Quarterly, 26, 331-348.

Bredo, E. \& Feinberg, W. (1982). Part two: The interpretive approach to social and educational research. In E. Bredo \& W. Feinberg, (eds.), Knowledge and Values in Social and Educational Research (pp. 115-128). Philadelphia, PA: Temple University Press.

Burt, R. (1982). Toward a Structural Theory of Action: Network Models of Social Structure, Perception, and Action, New York: Academic Press.

Burt, R. (1992). Structural Holes: The Structure of Competition, Cambridge, MA: Harvard University Press.

Carley, K. (1990). Structural constraints on communications: The diffusion of the homomorphic signal analysis technique through scientific fields. Journal of Mathematical Sociology, 15(3-4), 207-246.

Carley, K. (1991). A theory of group stability. American Journal of Sociology, 56(3), 331-354.

Carley, K. (2002). Smart agents and organizations of the future. In L. Lievrouw \& S. Livingstone, (eds.), The Handbook of New Media (pp. 206-220). London: Sage.

Carley, K. (2004). Dynamic network analysis. In R. Breiger, K. M. Carley, \& P. Pattison, (eds.), Dynamic Social Network Modeling and Analysis: 2002 Workshop Summary and Papers (pp. 133-145). Washington, DC: National Academies Press. 
Carley, K. \& Hill, V. (2001). Structural change and learning within organizations. In A. Lomi \& E. Larsen, (eds.), Dynamics of Organizations: Computational Modeling and Organization Theories (pp. 66-82). Menlo Park, CA: MIT Press/AAAI.

Carley, K., Kiesler, S., \& Wholey, D. (1993). Learning teamwork: Studies of training in software development. In Proceedings of the 1993 Coordination Theory and Collaboration Technology Workshop. National Science Foundation, Washington, D.C.

Carley, K. \& Krackhardt, D. (1996). Cognitive inconsistencies and non-symmetric friendship. Social Networks, 18(1).

Carley, K., Lee, J., \& Krackhardt, D. (2001). Destabilizing networks. Connections, 24(3), $31-34$.

Cohen, J. (1988). Statistical Power Analysis for the Behavioral Sciences, (2nd ed.). Hillsdale, NJ: Erlbaum.

Coff, R. (1997). Human assets and management dilemmas: Coping with hazards on the road to resource-based theory. Academy of Management Review, 22(2), 374-402.

Coff, R. (1999). When competitive advantage doesn't lead to performance: The resourcebased view and stakeholder bargaining power. Organization Science, 10(2), 119-133.

Coleman, J. (1988). Social capital in the creation of human capital. American Journal of Sociology, 94, 95-120.

Cook, T. \& Reichardt, C. (eds.). (1979). Qualitative and Quantitative Methods in Evaluation Research, Beverly Hills, CA: Sage.

Crozier, M. (1964). The Bureaucratic Phenomenon, Chicago: University of Chicago Press.

Dekker, D., Krackhardt, D., \& Snijders, T. (2003). Multicollinearity robust QAP for multiple regression. Presented at 1st Annual Conference of the North American Association for Computational Social and Organizational Science (June 22-25, 2003), Pittsburgh, PA.

Dubin, R. (1957). Power and union-management relations. Administrative Science Quarterly, 2, 60-81.

Dubin, R. (1963). Power, function and organization. Pacific Sociological Review, 6, 16-24.

Emerson, R. (1962). Power-dependence relations. American Sociological Review, 27, 31-41.

Espinosa, J., Kraut, R., Slaughter, S., Lerch, J., Herbsleb, J., \& Mockus, A. (2002). Shared mental models, familiarity, and coordination: A multi-method study of distributed software teams. In Proceedings of the 23rd International Conference on Information Systems, Barcelona, Spain.

Everett, M. \& Borgatti, S. (2002). The centrality of groups and classes. Journal of Mathematical Sociology, 23(3), 181-201.

Festinger, L., Schachter, S., \& Back, K. (1950). Social Pressures in Informal Groups: A Study of Human Factors in Housing, Palo Alto, CA: Stanford University Press.

Freeman, L. (1977). A set of measures of centrality based on betweenness. Sociometry, $40,35-41$.

Freeman, L. (1979). Centrality in social networks: Conceptual clarification. Social Networks, 1, 215-239.

Fullerton, H. \& Toossi, M. (2001, November). Employment outlook 2000-2010 - labor force projections to 2010: Steady growth and changing composition. Monthly Labor Review, 21-38.

Glaser, B. \& Strauss, A. (1967). The Discovery of Grounded Theory: Strategies for Qualitative Research, Chicago, IL: Aldine Publishing.

Goodman, P., Lerch, J., \& Mukhopadhyay, T. (1994). Individual and organizational productivity: Linkages and processes. In D. Harris, (ed.), Organizational Linkages: Understanding the Productivity Paradox (pp. 54-80). Washington, DC: National Academy Press.

Goodman, P. \& Whetten, D. (1998). Fifty years of organizational behavior from multiple perspectives. In M. Neufeld \& J. McKelvey, (eds.), Industrial Relations at the Dawn 
of the New Millennium (pp. 33-53). Ithaca, NY: Cornell School of Industrial and Labor Relations.

Graen, G. (1976). Role making processes within complex organizations. In M. Dunnette, (ed.), Handbook of Industrial and Organizational Psychology (pp. 1202-1245). Chicago, IL: Rand McNally.

Granovetter, M. (1985). Economic action and social structure: The problem of embeddedness. American Journal of Sociology, 91(3), 481-510.

Herriott, S., Levinthal, D., \& March, J. (1985). Learning from experience in organizations. American Economic Review, 75(2), 298-302.

Hickson, D., Hinings, C., Lee, C., Schneck, R., \& Pennings, J. (1971). A strategic contingencies' theory of intraorganizational power. Administrative Science Quarterly, 16(2), 216-229.

Hinds, P., Carley, K., Krackhardt, D., \& Wholey, D. (2000). Choosing workgroup members: The balance of similarity, competence, and familiarity. Organizational Behavior and Human Decision Processes, 81(2), 226-251.

Hinings, C., Hickson, D., Pennings, J., \& Schneck, R. (1974). Structural conditions of intraorganizational power. Administrative Science Quarterly, 19, 22-44.

Hollenbeck, J., Ilgen, D., Sego, D., Hedlund, J., Major, D., \& Phillips, J. (1995). The multi-level theory of team decision making: Decision performance in teams incorporating distributed expertise. Journal of Applied Psychology, 80, 292-316.

Hollenbeck, J., Ilgen, D., Phillips, J., \& Hedlund, J. (1994). Decision risk in dynamic twostage contexts: Beyond the status quo. Journal of Applied Psychology, 79, 592-598.

Hubert, L. \& Schultz, J. (1976). Quadratic assignment as a general data analysis strategy. British Journal of Mathematical \& Statistical Psychology, 29, 190-241.

Jick, T. (1983). Mixing qualitative and quantitative methods: Triangulation in action. In J. Van Maanen, (ed.), Qualitative Methodology (pp. 135-148). Beverly Hills, CA: Sage.

Jones, C., Hesterly, W., Fladmoe-Lindquist, K., \& Borgatti, S. (1998). Professional service constellations: How strategies and capabilities influence collaborative stability and change. Organization Science, 9(3), 396-410.

Kaufer, D. \& Carley, K. (1993). Communication at a Distance: The Effect of Print on Socio-Cultural Organization and Change, Hillsdale, NJ: Lawrence Erlbaum Associates.

Kiesler, S. \& Cummings, J. (2002). What do we know about Proximity and Distance in Work Groups? A Legacy of Research, Distributed Work, Cambridge, MA: MIT Press.

Kiesler, S., Wholey, D., \& Carley, K. (1994). Coordination as linkage: The case of software development teams. In D. Harris, (ed.), Organizational Linkages: Understanding the Productivity Paradox (pp. 214-239). Washington, DC: National Academy Press.

Kline, T. \& McGrath, J. (1998). Development and validation of five criteria for evaluating team performance. Organization Development Journal, 16(3), 9-28.

Korzenny, F. \& Bauer, C. (1981). Testing the theory of electronic propinquity: Organizational teleconferencing. Communication Research, 8, 479-498.

Krackhardt, D. (1987). Cognitive social structures. Social Networks, 9(2), 109-134.

Krackhardt, D. (1990). Assessing the political landscape: Structure, cognition and power in organizations. Administrative Science Quarterly, 35, 342-369.

Krackhardt, D. (1999). The ties that torture: Simmelian tie analysis in organizations. Research in the Sociolology of Organizations, 16, 183-210.

Krackhardt, D. \& Carley, K. (1998). A PCANS model of structure in organization. In Proceedings of the 1998 International Symposium on Command and Control Research and Technology (pp. 113-119). Monterrey, CA.

Krackhardt, D. \& Hanson, J. (1993). Informal networks: The company behind the chart. Harvard Business Review, 71(4), 104-111. 
Larson, J. \& Christenson, C. (1993). Groups as problem solving units: Toward a new meaning of social cognition. British Journal of Social Psychology, 32, 5-30.

Leavitt, H. (1996). The old days, hot groups, and managers' lib. Administrative Science Quarterly, 41, 288-300.

Levitt, B. \& March, J. (1988). Organizational learning. Annual Review of Sociology, 14, 319-340.

Liang, D., Moreland, R., \& Argote, L. (1995). Group versus individual training and group performance: The mediating role of transactive memory. Personality and Social Psychology Bulletin, 21, 384-393.

Lin, N. (2001). Social Capital: A Theory of Structure and Action, Cambridge, UK: Cambridge University Press.

Littlepage, G., Robison, W., \& Reddington, K. (1997). Effects of task experience and group experience on group performance, member ability, and recognition of expertise. Organizational Behavior and Human Decision Processes, 69(2), 133-147.

Maxwell, J., Bashook, P., \& Sandlow, L. (1986). Combining ethnographic and experimental methods in educational research: A case study. In D. Fetterman \& M. Pitman, (eds.), Educational Evaluation: Ethnography in Theory, Practice and Politics (pp.121-143). Beverly Hills, CA: Sage.

Mechanic, D. (1962). Sources of power of lower participants in complex organizations. Administrative Science Quarterly, 7, 349-364.

Mintzberg, H. (1983). Power in and Around Organizations, Saddle River, NJ: Prentice-Hall.

Monge, P. R., Rothman, L. W., Eisenberg, E. M., Miller, K. I., \& Kirste, K. K. (1985). The dynamics of organizational proximity. Management Science, 31, 1129-1141.

Mowday, R., Porter, L., \& Steers, R. (1982). Employee-Organization Linkages: The Psychology of Commitment, Absenteeism and Turnover, New York: Academic Press.

Oldham, G., Cummings, A., \& Zhou, J. (1995). The spatial configuration of organizations: A review of the literature and some new research directions. Research in Personnel and Human Resource Management, 13, 1-37.

Olson, G. \& Olson, J. (2000). Distance matters. Human-Computer Interaction, 15(1), 139-179.

Perrow, C. (1986). Complex Organizations: A Critical Essay, New York: McGraw Hill.

Perrow, C. (1984). Normal Accidents: Living with High Risk Technologies, New York: Basic.

Pisano, G., Bohmer, M., \& Edmondson, A. (2001). Organizational differences in rates of learning: Evidence from the adoption of minimally invasive surgery. Management Science, 47(6), 752-768.

Pfeffer, J. (1981). Power in Organizations, Marshfield, MA: Pitman.

Prietula, M. \& Simon, H. (1989). The experts in your midst. Harvard Business Review, 89(1), 120-124.

Price, J. (1977). The Study of Turnover, Ames, IA: Iowa State University Press.

Proctor, C. \& Loomis, C. (1951). Analysis of sociometric data. In M. Jahoda, M. Deutsch, \& S. Cook, (eds.), Research Methods in Social Relations (pp. 561-585). New York: Dryden.

Schreiber, C. \& Carley, K. (2004). Going beyond the data: Empirical validation leading to grounded theory. Computational and Mathematical Organization Theory, 10(2), $115-164$.

Senge, P. (1990). The Fifth Discipline: The Art and Practice of the Learning Organization, New York: Doubleday.

Sokal, R. \& Michener, C. (1958). A statistical method for evaluating systematic relationships. University of Kansas Science Bulletin, 38, 1409-1438.

Stephenson, K. \& Zelen, M. (1989). Rethinking centrality: Methods and applications. Social Networks, 11, 1-37. 
Stewart, T. A. (2001, May 28). Intellectual capital: Brainpower. Fortune.

Swets, J. A. (1995). Signal Detection Theory and ROC Analysis in Psychology and Diagnostics: Collected Papers, Mahwah, NJ: Lawrence Erlbaum Associates.

Tape, T. G. (2002). Interpreting Diagnostic Tests: The Area Under an ROC Curve. Retrieved December 4, 2002, from University of Nebraska Medical Center Diagnostic Tests Web site: http://gim.unmc.edu/dxtests/ROC3.htm

Thomas-Hunt, M., Ogden, T., \& Neale, M. (2003). Who's really sharing: Effects of social and expert status on knowledge exchange within groups. Organization Science (special issue on "Managing Knowledge in Organizations.")

Thompson, J. D. (1967). Organizations in Action, New York: McGraw-Hill.

Van Maanen, J. (1983). Qualitative Methodology, Beverly Hills, CA: Sage.

Wasserman, S. \& Faust, K. (1994). Social Network Analysis, Cambridge, UK: Cambridge University Press.

Wernerfelt, B. (1984). A resource-based view of the firm. Strategic Management Journal, $5(2), 171-180$.

Yin, R. (1984). Case Study Research: Design and Methods, Beverly Hills, CA: Sage.

\section{APPENDIX}

APPENDIX A Actor Vector

\begin{tabular}{rcl}
\hline 1 & LDR & Project Manager \\
2 & M1 & Art Director \\
3 & M2 & Technical Lead \\
4 & S1 & Design Lead \\
5 & S2 & Interactive Lead \\
6 & S3 & Data Architect \\
7 & S4 & Application Architect \\
8 & EE1 & Designer \\
9 & EE2 & Web Developer \\
10 & EE3 & Usability Engineer \\
11 & EE4 & Business Analyst 1 \\
12 & EE5 & Business Analyst 2 \\
13 & EE6 & Software Engineer 1 \\
14 & EE7 & Software Engineer 2 \\
15 & EE8 & Software Engineer 3 \\
16 & EE9 & Software Engineer 4 \\
\hline
\end{tabular}


APPENDIX B Knowledge Vector

\begin{aligned} & \hline S1 Project Management Training/Experience \\ & S2 Administrative Training \\ & S3 Software Engineering Experience \\ & S4 Team Supervision Experience \\ & S5 General Programming Supervision Experience \\ & S6 Application Architecture Design \\ & S7 Creative Design \\ & S8 Screen Design \\ & S9 Network Management \\ & S10 Data Modeling \\ & S11 Database Programming \\ & S12 Content Design and Development \\ & S13 Usability/Navigation Design \\ & S14 Web Development (HTML) \\ & S15 ATG Dynamo Platform \\ & S16 Unix/Java/C + + Programming \\ & S17 Interwoven Platform \\ & S18 Interface Design/Development \\ & S19 Apache Platform \\ & \hline\end{aligned}

APPENDIX C Task Vector

\begin{aligned} & \hline T1 Project Management \\ & T2 Administration \\ & T3 Detailed Supervision \\ & T4 Reporting \\ & T5 Usability/Wireframe \\ & T6 Comps Design \\ & T7 Content Development \\ & T8 Screen Design \\ & T9 Application \& Network Management \\ & T10 Data Model \\ & T11 Application Architecture - Flows \\ & T12 Application Architecture - Content Management \\ & T13 Application Architecture - Screen Objects \\ & T14 Application Architecture - Interface Design \\ & T15 Application Architecture - Technology Platform \\ & T16 Development - Data Repository \\ & T17 Development - Screens \\ & T18 Development - Content \\ & T19 Development - Interfaces \\ & T20 Testing - Integration \\ & T21 Testing - System \\ & T22 Testing - User Acceptance \\ & T23 Migration \\ & T24 Deployment \\ & \hline\end{aligned}


APPENDIX D Social Network Matrix $\left(N \equiv N_{\widehat{n} \times \widehat{n}}\right)$

LDR M1 M2 S1 S2 S3 S4 EE1 EE2 EE3 EE4 EE5 EE6 EE7 EE8 EE9

\begin{tabular}{lllllllllllllllll}
\hline LDR & 0 & 1 & 1 & 1 & 0 & 0 & 1 & 0 & 1 & 0 & 0 & 0 & 0 & 1 & 0 & 0 \\
M1 & 1 & 0 & 1 & 1 & 1 & 0 & 0 & 0 & 1 & 0 & 0 & 0 & 0 & 0 & 0 & 0 \\
M2 & 1 & 1 & 0 & 1 & 0 & 1 & 1 & 0 & 1 & 0 & 0 & 1 & 0 & 1 & 0 & 0 \\
S1 & 1 & 1 & 1 & 0 & 1 & 0 & 0 & 1 & 1 & 0 & 0 & 0 & 0 & 0 & 0 & 0 \\
S2 & 0 & 1 & 0 & 1 & 0 & 0 & 0 & 0 & 0 & 1 & 0 & 0 & 0 & 0 & 0 & 0 \\
S3 & 0 & 0 & 1 & 0 & 0 & 0 & 1 & 0 & 0 & 0 & 1 & 1 & 0 & 0 & 0 & 0 \\
S4 & 1 & 0 & 1 & 0 & 0 & 1 & 0 & 0 & 0 & 0 & 0 & 0 & 1 & 1 & 1 & 1 \\
EE1 & 0 & 0 & 0 & 1 & 0 & 0 & 0 & 0 & 1 & 0 & 1 & 0 & 0 & 1 & 0 & 0 \\
EE2 & 1 & 1 & 1 & 1 & 0 & 0 & 0 & 1 & 0 & 0 & 0 & 0 & 0 & 1 & 0 & 0 \\
EE3 & 0 & 0 & 0 & 0 & 1 & 0 & 0 & 0 & 0 & 0 & 0 & 0 & 0 & 0 & 0 & 0 \\
EE4 & 0 & 0 & 0 & 0 & 0 & 1 & 0 & 1 & 0 & 0 & 0 & 1 & 0 & 1 & 0 & 0 \\
EE5 & 0 & 0 & 1 & 0 & 0 & 1 & 0 & 0 & 0 & 0 & 1 & 0 & 0 & 0 & 0 & 1 \\
EE6 & 0 & 0 & 0 & 0 & 0 & 0 & 1 & 0 & 0 & 0 & 0 & 0 & 0 & 1 & 0 & 1 \\
EE7 & 1 & 0 & 1 & 0 & 0 & 0 & 1 & 1 & 1 & 0 & 1 & 0 & 1 & 0 & 0 & 1 \\
EE8 & 0 & 0 & 0 & 0 & 0 & 0 & 1 & 0 & 0 & 0 & 0 & 0 & 0 & 0 & 0 & 0 \\
EE9 & 0 & 0 & 0 & 0 & 0 & 0 & 1 & 0 & 0 & 0 & 0 & 1 & 1 & 1 & 0 & 0 \\
\hline
\end{tabular}




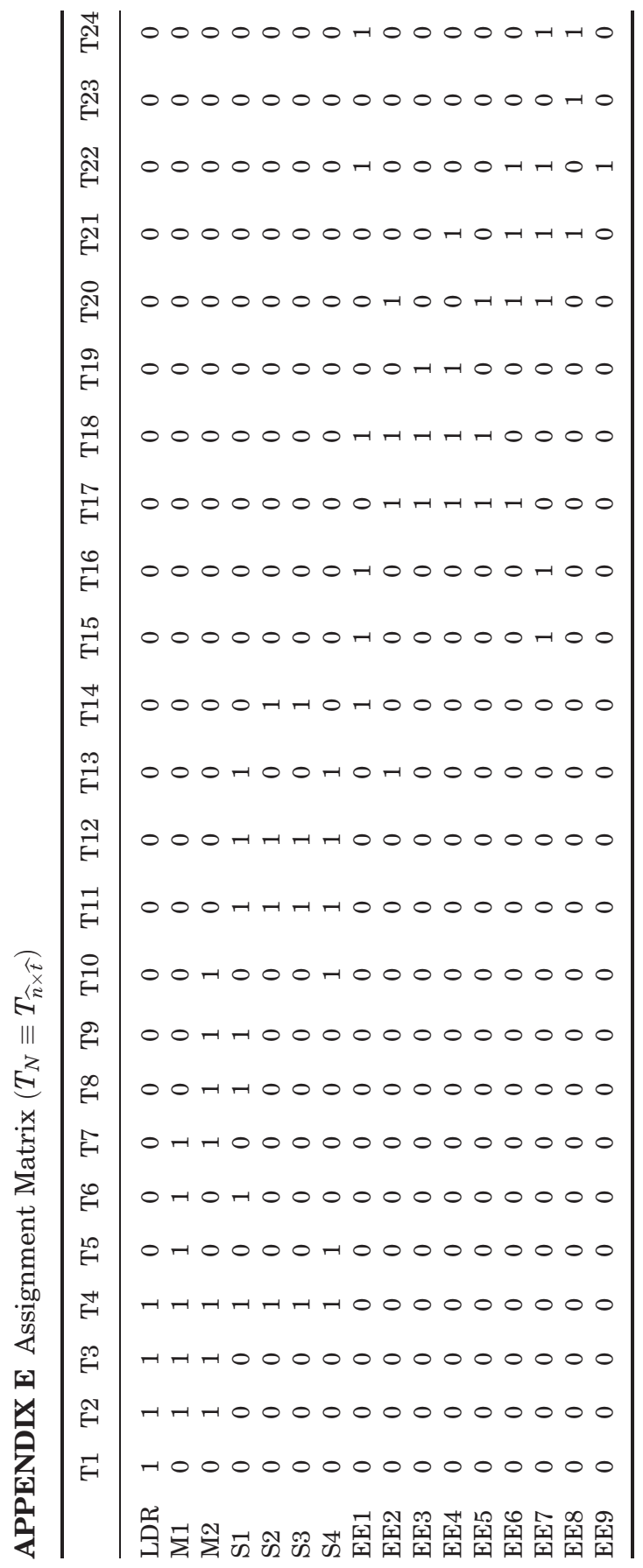


APPENDIX F Raw Skill/Knowledge Matrix $\left(S_{N} \equiv S_{\widehat{n} \times \widehat{n}}\right)$

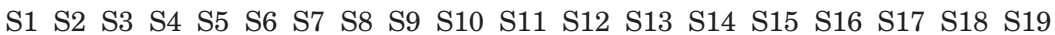

\begin{tabular}{llllllllllllllllllll}
\hline LDR & 1 & 1 & 1 & 0 & 0 & 1 & 0 & 1 & 0 & 0 & 1 & 1 & 0 & 1 & 0 & 0 & 0 & 0 & 0 \\
M1 & 0 & 1 & 0 & 1 & 0 & 1 & 1 & 1 & 1 & 0 & 0 & 1 & 0 & 0 & 1 & 0 & 1 & 0 & 0 \\
M2 & 0 & 1 & 1 & 1 & 1 & 0 & 0 & 1 & 1 & 1 & 1 & 0 & 0 & 1 & 0 & 0 & 1 & 0 & 0 \\
S1 & 0 & 0 & 1 & 0 & 0 & 0 & 1 & 1 & 0 & 1 & 1 & 0 & 0 & 0 & 1 & 0 & 0 & 0 & 0 \\
S2 & 0 & 0 & 1 & 0 & 0 & 1 & 0 & 0 & 1 & 0 & 0 & 0 & 0 & 1 & 1 & 1 & 0 & 0 & 0 \\
S3 & 0 & 0 & 1 & 0 & 0 & 1 & 0 & 1 & 0 & 0 & 1 & 1 & 0 & 1 & 1 & 0 & 0 & 0 & 0 \\
S4 & 0 & 0 & 1 & 0 & 1 & 1 & 0 & 0 & 0 & 0 & 0 & 1 & 0 & 0 & 0 & 0 & 0 & 1 & 1 \\
EE1 & 0 & 0 & 0 & 0 & 0 & 0 & 0 & 0 & 0 & 0 & 0 & 1 & 0 & 1 & 1 & 1 & 0 & 1 & 0 \\
EE2 & 0 & 0 & 0 & 0 & 0 & 0 & 0 & 0 & 0 & 0 & 0 & 0 & 0 & 1 & 0 & 1 & 1 & 0 & 0 \\
EE3 & 0 & 0 & 0 & 0 & 0 & 0 & 0 & 0 & 0 & 0 & 0 & 0 & 1 & 1 & 0 & 1 & 0 & 0 & 0 \\
EE4 & 0 & 0 & 0 & 0 & 0 & 0 & 0 & 0 & 0 & 0 & 1 & 1 & 0 & 0 & 1 & 1 & 0 & 0 & 0 \\
EE5 & 0 & 0 & 0 & 0 & 0 & 0 & 0 & 0 & 0 & 0 & 0 & 0 & 0 & 1 & 0 & 1 & 1 & 0 & 0 \\
EE6 & 0 & 0 & 0 & 0 & 0 & 0 & 0 & 0 & 0 & 0 & 0 & 0 & 0 & 1 & 1 & 1 & 0 & 0 & 1 \\
EE7 & 0 & 0 & 0 & 0 & 0 & 0 & 0 & 0 & 0 & 0 & 0 & 0 & 0 & 1 & 1 & 0 & 0 & 0 & 0 \\
EE8 & 0 & 0 & 0 & 0 & 0 & 0 & 0 & 0 & 0 & 0 & 0 & 0 & 0 & 1 & 0 & 1 & 0 & 1 & 0 \\
EE9 & 0 & 0 & 0 & 0 & 0 & 0 & 0 & 0 & 0 & 0 & 0 & 1 & 0 & 0 & 0 & 1 & 0 & 1 & 0 \\
\hline
\end{tabular}

